\title{
EFEITO DO TAMANHO DO FOLÍCULO NA MATURAÇÃO NUCLEAR E CITOPLASMÁTICA DE OVÓCITOS DE FÊMEAS ZEBUÍNAS ${ }^{1}$
}

\author{
MARGOT ALVES NUNES DODE², NORMA CLÉA RODOVALHO ${ }^{3}$, \\ VANESSA GOMES UENO ${ }^{4}$ e RAFAEL GERALDO DE OLIVEIRA ALVES 5
}

\begin{abstract}
RESUMO - Este estudo avaliou o efeito do tamanho do folículo na capacidade dos ovócitos de sofrerem maturação nuclear e citoplasmática. Ovários de vacas Nelore (Bos indicus) foram coletados logo após o abate, e os complexos cúmulus-ovócitos foram aspirados de folículos de diferentes categorias, e classificados de acordo com seus diâmetros em: 1-2 mm, 3-5 mm, 6-8 mm e $\geq 9 \mathrm{~mm}$. A medida do diâmetro e a fixação dos ovócitos para avaliação do estádio nuclear antes da maturação foram feitas logo após a aspiração. Ovócitos morfologicamente viáveis foram maturados, fecundados e cultivados in vitro. Os ovócitos obtidos de folículos de $1-2 \mathrm{~mm}$ apresentaram menor diâmetro $(\mathrm{P}<0,01)$ do que os dos demais grupos. Antes da maturação, $89,8 \%, 90,1 \%, 85,7 \%$ e $100 \%$ dos ovócitos provenientes de folículos de 1-2, 3-5, 6-8 e $\geq 9$ mm de diâmetro, respectivamente, apresentavam vesícula germinativa. $\mathrm{O}$ tamanho do folículo não influenciou $(\mathrm{P}<0,05)$ a taxa de maturação nuclear. A porcentagem de ovócitos que chegaram a metáfase II foi de $88,8 \%, 87,8 \%, 92,9 \%$ e $100 \%$ no que se refere aos ovócitos de folículos de 1-2, 3$5,6-8$ e $\geq 9 \mathrm{~mm}$, respectivamente. As taxas de penetração e clivagem foram semelhantes $(\mathrm{P}>0,05)$ nos grupos de $1-2 \mathrm{~mm}(93,4 \%$ e $81,9 \%), 3-5 \mathrm{~mm}(90,7 \%$ e $79,6 \%), 6-8 \mathrm{~mm}(91,3 \%$ e $77,8 \%)$ e $\geq 9 \mathrm{~mm}$ $(92,0 \%$ e $78,3 \%)$. Da mesma forma, não houve diferenças $(\mathrm{P}>0,05)$ entre as categorias de folículos no que se refere às taxas de polispermia, descondensação da cabeça do espermatozóide e formação de pronúcleos. Os resultados deste estudo demonstram que na espécie $B$. indicus, folículos com diâmetro de $1 \mathrm{~mm}$ até $\geq 9 \mathrm{~mm}$ não influenciaram a capacidade dos ovócitos de reiniciar e completar a meiose e de clivar após maturação e fecundação in vitro.
\end{abstract}

Termos para indexação: bovino, diâmetro folicular, competência meiótica, Nelore, Bos indicus.

\section{EFFECT OF FOLLICLE SIZE IN NUCLEAR AND CYTOPLASMIC MATURATION OF OOCYTES FROM ZEBU COWS}

\begin{abstract}
The objective of this study was to investigate the effect of follicle size on the ability of the oocytes to undergo nuclear and cytoplasmic maturation. Ovaries from Nelore cows (Bos indicus) were collected just after slaughter. The cumulus oocyte complexes were aspirated from four size categories follicles: 1-2 mm, 3-5 mm, 6-8 $\mathrm{mm}$ and $\geq 9 \mathrm{~mm}$ of diameter. The oocytes were measured and evaluated for chromatin configuration before maturation. After selection the oocytes were matured, fertilized and cultured in vitro. Oocytes obtained from follicles of 1-2 mm showed a smaller diameter $(\mathrm{P}<0.01)$ than the other follicle groups. Before maturation $89.8 \%, 90.1 \%, 85.7 \%$ and $100 \%$ of oocytes from follicles of 1-2 mm, 3-5 mm, 6-8 $\mathrm{mm}$ and $\geq 9 \mathrm{~mm}$, respectively, showed a germinal vesicle. A similar maturation rate $(\mathrm{P}<0.05)$ was observed for all groups, with $88.8 \%, 87.8 \%, 92.9 \%$ and $100.0 \%$ of the oocytes in metaphase II for follicles of 1-2, 3-5, 6-8 and $\geq 9 \mathrm{~mm}$, respectively. The penetration and clivage rates were also similar $(\mathrm{P}>0.05)$ for oocytes obtained from follicle of $1-2 \mathrm{~mm}(93.4 \%$ and $81.9 \%), 3-5 \mathrm{~mm}(90.7 \%$ and $79.6 \%), 6-8 \mathrm{~mm}(91.3 \%$ and $77.8 \%)$ and $\geq 9 \mathrm{~mm}(92.0 \%$ and $78.3 \%)$. In addition, there were no differences $(\mathrm{P}>0.05)$ among follicles groups on the percentage of oocytes showing polispermy, decondensed sperm head and pronuclei formation. The results of this experiment showed that oocytes obtained from 1-2 mm to $\geq 9 \mathrm{~mm}$ follicles, from Bos indicus, have similar capability to undergo in vitro maturation and fertilization as the larger follicles.
\end{abstract}

Index terms: bovine, follicular diameter, meiotic competence, Nelore, Bos indicus.

\footnotetext{
${ }^{1}$ Aceito para publicação em 18 de março de 1999.

${ }^{2}$ Méd. Vet., Ph.D., Embrapa-Centro Nacional de Pesquisa de Gado de Corte (CNPGC), Caixa Postal 154, CEP 79002-970,
}

Campo Grande, MS. E-mail: margot@cnpgc.embrapa.br ${ }^{3}$ Aluno do curso de Biologia. Bolsista da Embrapa-CNPGC. ${ }^{4}$ Méd. Vet. Bolsista da Fundapam.

${ }^{5}$ Eng. Agrôn., Ph.D., Embrapa-CNPGC. 


\section{INTRODUÇÃO}

Durante a ovogênese, os ovócitos de mamíferos permanecem retidos no estádio de diplóteno da prófase da primeira divisão meiótica, desde a vida fetal até pouco antes da ovulação. O reinício da meiose ou saída do estádio de diplóteno pode ser mediada por um estímulo hormonal in vivo, ou simplesmente pela retirada do ovócito de dentro do folículo (Wassarman \& Albertini, 1994). Entretanto, somente ovócitos competentes têm a capacidade de completar a meiose. Essa competência para maturar é adquirida durante o crescimento ovocitário, e pode ser descrita como a capacidade de quebrar a vesícula germinativa, progredir do estágio de prófase I até metáfase II e sustentar o desenvolvimento embrionário após a fecundação (Eppig, 1991). Portanto, já é conhecido que tanto a maturação nuclear como a citoplasmática devem ocorrer normalmente para que se possam obter embriões viáveis in vitro.

Ovócitos em crescimento não são capazes de reiniciar e completar a meiose e são tidos como meioticamente incompetentes (Arlotto et al., 1996), passando a ser competentes quando completam o seu crescimento. Em contraste com os ovócitos de roedores, que adquirem a competência meiótica com a formação do antro (Bar-Amir \& Tsafriri, 1981), os das espécies domésticas não têm essa capacidade quando o antro é formado (Motlik et al., 1984). Ovócitos bovinos para maturação in vitro (MIV) são, geralmente, coletados de folículos antrais de 1-8 mm de diâmetro. Entretanto, a completa competência para maturar parece ser adquirida somente quando os folículos atingem em torno de $3 \mathrm{~mm}$ (Fair et al., 1995). Além disso, tem sido demonstrado que ovócitos coletados de folículos de 1-2 mm não têm capacidade de se desenvolver in vitro (Pavlok et al., 1992), ao passo que os coletados de folículos de $6 \mathrm{~mm}$ ou mais têm maior potencial de desenvolvimento (Lonergan et al., 1994).

Considerando que a competência para completar a meiose pode estar relacionada com o tamanho do folículo do qual o ovócito foi obtido, esse fator parece afetar significativamente o potencial de desenvolvimento dos ovócitos maturados e fecundados in vitro. Entretanto, a relação entre o tamanho dos folículos e a aquisição da competência meiótica ainda não foi estudada em bovinos Bos indicus.

Animais zebuínos (B. indicus) contribuem com cerca de $80 \%$ do rebanho nacional, além de serem também predominantes em outros países tropicais e subtropicais. Diferenças quanto aos aspectos reprodutivos entre $B$. indicus e Bos taurus, têm sido demonstradas por diversos autores. Os ovários e o corpo lúteo de fêmeas zebuínas são menores que os de fêmeas taurinas (Mutiga et al., 1993), e apresentam também menor número de folículos por ovário, e com menor diâmetro (Figueiredo et al., 1995). Com a crescente utilização das técnicas para produção de embriões a partir de ovócitos maturados in vitro, assim como a utilização desses ovócitos em outras biotécnicas - como a clonagem -, aumentou a demanda de ovócitos que tenham maior potencial de desenvolvimento.

O estudo teve por objetivo verificar o efeito do tamanho folicular na capacidade de desenvolvimento in vitro dos ovócitos, e identificar, em fêmeas zebuínas, o tamanho do folículo mais adequado para obtenção de ovócitos competentes que possam sofrer a maturação completa in vitro.

\section{MATERIAL E MÉTODOS}

\section{Coleta, cultivo e avaliação de ovócitos}

Ovários de fêmeas Nelore foram coletados imediatamente após o abate e transportados em frascos contendo solução salina estéril $(\mathrm{NaCl} 0,9 \%)$ acrescida de $100 \mathrm{UI} / \mathrm{mL}$ de penicilina e $100 \mu \mathrm{g} / \mathrm{mL}$ de estreptomicina, a uma temperatura de $35-37^{\circ} \mathrm{C}$. No laboratório, os ovários foram lavados em solução salina fosfatada modificada (D-PBS), e os folículos visíveis na superfície dos ovários foram aspirados com uma agulha $18 \mathrm{G}$ acoplada a uma seringa de $5 \mathrm{~mL}$.

Antes da aspiração, os folículos foram classificados em quatro categorias de acordo com seu diâmetro: pequeno (P: 1-2 mm), médio (M: 3-5 mm), grande (G: 6-8 mm) e pré-ovulatórios (PO: $\geq 9 \mathrm{~mm})$. O líquido aspirado contendo os ovócitos foi colocado em tubos cônicos de $15 \mathrm{~mL}$ separados para cada tamanho folicular. Esses foram deixados em repouso por 20 minutos, e após esse período o sedimentado contendo os ovócitos foi removido e colocado em placas de Petri contendo D-PBS suplementado com $10 \%$ de soro fetal bovino (FCS) e antibióticos. Somente ovócitos com citoplasma uniforme e circundados por vá- 
rias camadas compactas de células do cúmulus foram selecionados para as avaliações e cultivo. Os complexos cúmulus-ovócitos das diferentes categorias de folículos foram maturados in vitro por 24 horas em meio TCM-199 suplementado com $10 \%$ FCS (v/v), $5,0 \mu \mathrm{g} / \mathrm{mL}$ de $\mathrm{LH}$, $0,5 \mu \mathrm{g} / \mathrm{mL}$ de $\mathrm{FSH}$ e antibióticos $(100 \mathrm{UI} / \mathrm{mL}$ de penicilina e $100 \mu \mathrm{g} / \mathrm{mL}$ de estreptomicina) sob óleo mineral. Todos os cultivos foram feitos em atmosfera de $5 \%$ de $\mathrm{CO}_{2}$ a uma temperatura de $38,5^{\circ} \mathrm{C}$.

Alguns ovócitos foram retirados do pool selecionado para avaliação da configuração da cromatina antes da maturação. Os ovócitos avaliados antes e após a maturação foram desnudados e fixados em solução de ácido acético:alcool (1:3) por pelo menos 24 horas. Os ovócitos fixados foram então corados com solução de 1\% lacmóide em $45 \%$ de ácido acético glacial. Cada ovócito foi avaliado em microscópio de contraste de fase e classificado de acordo com o estágio de maturação determinado pela morfologia dos cromossomas.

O diâmetro dos ovócitos desnudos (incluindo a zona pelúcida) foi medido antes da maturação, por meio de um microscópio de luz invertida, com uma ocular contendo uma régua, o qual havia sido previamente calibrado com um micrômetro.

\section{Fecundação in vitro (FIV)}

Para FIV foi utilizado sêmen congelado, proveniente de um único animal e da mesma partida. Após o descongelamento, o sêmen foi separado pela técnica de swim-up (Parrish et al., 1995), e adicionado no meio de fecundação em uma concentração final de $1 \times 10^{6}$ espermatozóides $/ \mathrm{mL}$. O meio para fecundação utilizado foi o IVF-TALP (Parrish et al., 1986) contendo penicilamina $(2 \mathrm{mM})$, hipotaurina (250 mM), epinefrina e heparina $(10 \mu \mathrm{g} / \mathrm{mL})$. Os ovócitos maturados in vitro de cada categoria de folículo foram lavados três vezes no meio de fecundação e colocados em gotas de $150 \mu \mathrm{L}$, sob óleo mineral. Os espermatozóides e ovócitos foram incubados por um período de 18 horas, a $38,5^{\circ} \mathrm{C}$, a $5 \%$ de $\mathrm{CO}_{2}$.

\section{Cultivo e avaliação embrionária}

Após a incubação dos espermatozóides e dos ovócitos por 18 horas, os zigotos foram lavados e transferidos para o meio de cultivo embrionário. O meio de cultivo utilizado foi o TCM-199, suplementado com 10\% FCS (v/v), nistatina, gentamicina e células epiteliais de oviduto bovino. Os ovidutos foram coletados em frigoríficos, quando da coleta dos ovários, e as células epiteliais foram obtidas por lavagens sucessivas da luz dos ovidutos, e mantidas em cultivo até a sua utilização. Quarenta e quatro horas após a inseminação in vitro, o estádio de desenvolvimento embrionário foi avaliado para determinar o número de embriões clivados. Os não-clivados foram fixados e corados, como já mencionado anteriormente, para avaliar polispermia, descondensação da cabeça do espermatozóide e a formação dos pro-núcleos masculino e feminino.

\section{Desenho experimental}

O primeiro experimento foi realizado para verificar o diâmetro dos ovócitos obtidos de diferentes tamanhos de folículos em fêmeas zebuínas. Os folículos foram agrupados em diferentes categorias, de acordo com seu tamanho: 1-2, 3-5, 6-9 e $\geq 9 \mathrm{~mm}$, e aspirados. Os ovócitos de cada categoria foram selecionados e desnudados, para determinação do diâmetro.

No segundo experimento, foi avaliado o estádio nuclear dos ovócitos dos diferentes tamanhos foliculares antes da maturação, assim como a capacidade desses ovócitos de reiniciarem a meiose e progredir até o estágio de metáfase II. Os ovócitos foram fixados e corados antes e depois da maturação in vitro, e foram classificados, de acordo com a morfologia da cromatina, nos estágios a seguir: vesícula germinativa (VG), prometáfase (PM), metáfase I, anáfase I, telófase I e metáfase II. Os ovócitos degenerados foram excluídos da análise.

$\mathrm{O}$ terceiro experimento foi realizado para avaliar a capacidade de desenvolvimento dos ovócitos obtidos de diferentes tamanhos de folículos. Após a maturação, os ovócitos com as células do cúmulus expandidas foram selecionados para FIV. Nos resultados, foram considerados os ovócitos morfologicamente viáveis que clivaram até 44 horas após a inseminação. Os que não clivaram, foram fixados, corados e avaliados para presença de polispermia, descondensação da cabeça e pro-núcleos masculino e feminino.

Os dados de diâmetro dos ovócitos foram submetidos à analise da variância, procedimento GLM (SAS, 1985) onde foi testado o efeito do tamanho de folículo. Foi também feita análise de correlação entre o tamanho de folículo e diâmetro dos ovócitos. Os resultados referentes à maturação nuclear e citoplasmática foram analisados por meio de $\chi$-quadrado.

\section{RESULTADOS E DISCUSSÃO}

O diâmetro médio dos ovócitos das diferentes categorias de folículos, determinado imediatamente após a aspiração e a desnudação, são apresentados na Tabela 1. Embora o diâmetro dos ovócitos tenha variado, em média, de 154,7 $\mu \mathrm{m}$ à $164,4 \mu \mathrm{m}$ foi obser- 
vado um efeito significativo $(\mathrm{P}<0,001)$ do tamanho do folículo no diâmetro dos ovócitos. Verificou-se que ovócitos obtidos de folículos pequenos (1-2 mm) apresentaram menor diâmetro do que os provenientes de folículos médios, grandes ou pré-ovulatórios $(\geq 3 \mathrm{~mm})$.

Vários estudos têm demonstrado que a capacidade de desenvolvimento in vitro de ovócitos bovinos pode ser afetada pelo tamanho e qualidade dos folículos dos quais são obtidos (Lonergan et al., 1994; Sirard \& Blodin, 1996). Tem sido demonstrado (Fair et al., 1995) que ovócitos de folículos pequenos $(\leq 2 \mathrm{~mm})$ têm um diâmetro menor e uma menor capacidade de realizar o rompimento da vesícula germinativa e de chegar à metáfase I (Fair et al., 1995). Somente ovócitos de folículos maiores $(\geq 6 \mathrm{~mm})$ têm capacidade de sofrer maturação nuclear e citoplásmatica e de se desenvolver até o estádio de blastocisto (Sirard \& Blodin, 1996). Entretanto, a relação entre a formação do antro, a obtenção da competência meiótica e o tamanho do folículo não foi ainda estudada em bovinos $B$. indicus.

No presente estudo, o diâmetro dos ovócitos foi menor $(\mathrm{P}<0,05)$ nos folículos de 1-2 mm, enquanto os de folículos maiores do que $3 \mathrm{~mm}$ apresentavam diâmetros semelhantes (Tabela 1). Esses resultados discordam dos obtidos por Arlotto et al. (1996), que observaram que os ovócitos de B. taurus continuavam a crescer em folículos antrais de até $15 \mathrm{~mm}$ (pré-ovulatórios). Esse crescimento contínuo não foi observado em zebuínos; no presente estudo, houve um aumento no diâmetro dos ovócitos de folículos de 1-2 mm para os de 3-5 mm. Entretanto, não foram observadas mudanças significativas no diâme-

TABELA 1. Número e diâmetro de ovócitos, de acordo com o tamanho do folículo em vacas Nelore.

\begin{tabular}{ccc}
\hline $\begin{array}{c}\text { Tamanho do } \\
\text { folículo }(\mathrm{mm})\end{array}$ & Número & $\begin{array}{c}\text { Diâmetro } \pm \\
\text { desvio-padrão }(\mu \mathrm{m})^{1}\end{array}$ \\
\hline $1-2$ & 229 & $154,7 \pm 11,6 \mathrm{a}$ \\
$3-5$ & 235 & $160,7 \pm 9,7 \mathrm{~b}$ \\
$6-8$ & 80 & $159,8 \pm 9,2 \mathrm{~b}$ \\
$\geq 9$ & 19 & $164,4 \pm 9,1 \mathrm{~b}$ \\
\hline
\end{tabular}

1 Valores seguidos de letras desiguais na mesma coluna diferem significativamente $(\mathrm{P}<0,001)$ pelo método de quadrados mínimos. tro a partir de $3 \mathrm{~mm}$, o que pode ser confirmado pelo baixo coeficiente de correlação obtido quando se considerou essas duas variáveis.

A avaliação do estádio nuclear dos ovócitos obtidos de diferentes tamanhos de folículos antes da maturação in vitro foi realizada logo após a aspiração. Para evitar qualquer alteração nos resultados durante o processo de manipulação, os ovócitos foram mantidos em líquido folicular até o momento da desnudação. Logo após serem desnudados foram fixados e posteriormente corados. O estádio nuclear dos ovócitos antes da maturação foi semelhante $(\mathrm{P}>0,05)$ nos vários grupos de folículos (Tabela 2 ), e mais de $80 \%$ dos ovócitos, independentemente da categoria folicular, encontrava-se em estádio de vesícula germinativa (VG), o que identifica ovócitos imaturos. Dos que apresentavam rompimento da VG, apenas $2,9 \%$ e $2,8 \%$ do grupo de folículos médios e pequenos, respectivamente, atingiram o estádio de metáfase I (MI). Esses resultados são semelhantes aos obtidos por Sirard \& Coenen (1994) no tocante a ovócitos de fêmeas taurinas.

O pequeno número de ovócitos obtidos no grupo de folículos pré-ovulatórios, dada a baixa incidência destes nos ovários, prejudicou a análise dessa categoria. Os folículos maiores do que $6 \mathrm{~mm}$, e em especial os acima de $9 \mathrm{~mm}$ representam uma porção muito pequena dos folículos antrais presentes nos ovários de zebuínos (Dominguez, 1995). A baixa ocorrência desses folículos tem dificultado os estudos que utilizam diferentes categorias foliculares.

Somente ovócitos com citoplasma uniforme e várias camadas compactas de células do cúmulus foram utilizados para maturação in vitro. Não houve diferença $(\mathrm{P}>0,05)$ na taxa de maturação dos ovócitos de diferentes tamanhos de folículos, pois mais de $80 \%$ atingiram o estádio de MII em um período de 24 horas, em todos os grupos (Tabela 3). As taxas de maturação obtidas são semelhantes às citadas na literatura quanto a B. taurus (Kim et al., 1996; Gandolfi et al., 1997). Entretanto, quando o tamanho dos folículos foi considerado, Pavlok et al. (1992) e Fair et al. (1995) mostraram que em ovócitos provenientes de folículos menores do que $2 \mathrm{~mm}$ a taxa de maturação nuclear é menor do que em ovócitos de folículos acima de $3 \mathrm{~mm}$. Essa diferença não foi observada no presente estudo. 
A competência para maturar é adquirida progressivamente durante o crescimento folicular, e o fato de ovócitos chegarem ao estádio de MII in vitro não necessariamente significa que eles sejam competentes para suportar uma fecundação normal e posterior desenvolvimento embrionário in vitro (Crozet et al., 1995). Isso demonstra que a capacidade de completar a maturação citoplasmática se desenvolve além da capacidade de completar a maturação nuclear.

Para avaliar a maturação citoplasmática, ovócitos dos diferentes tamanhos de folículos foram fecundados in vitro. Foi observado que as taxas de penetração e clivagem após a MIV e a FIV foram semelhantes ovócitos provenientes de diferentes tamanhos de folículos (Tabela 4). As taxas obtidas neste trabalho, independentemente do tamanho folícular, foram similares às obtidas por outros autores (Lonergan et al., 1994; Smith et al., 1996; Gandolfi et al., 1997) utilizando ovócitos de folículos maiores do que $3 \mathrm{~mm}$.
A ocorrência de anormalidades na fecundação, como, por exemplo, uma falha na descondensação da cabeça do espermatozóide ou a formação de prónúcleos, que são causados pela insuficiência na maturação citoplasmática, foi semelhante $(\mathrm{P}>0,05)$ nos vários grupos (Tabela 4). Cerca de $80 \%$ dos ovócitos foram fecundados normalmente e clivaram; e dos que não clivaram, a maioria foi capaz de formar os pro-núcleos masculino e feminino (Tabela 4).

Apesar de a taxa de polispermia não ter sido diferente $(\mathrm{P}>0,05)$ nos grupos, os ovócitos provenientes de folículos pré-ovulatórios apresentaram uma taxa superior aos demais. Devido ao pequeno número de observações sobre esse grupo, não foi possível avaliar a significância biológica da polispermia.

A maturação representa o estágio final da preparação do ovócito para a fecundação. Portanto, mudanças estruturais e bioquímicas ocorrem durante esse período e são essenciais para completar a meiose

TABELA 2. Número e estádio nuclear dos ovócitos obtidos de diferentes tamanhos de folículos antes da maturação in vitro, em vacas Nelore ${ }^{1}$.

\begin{tabular}{ccccc}
\hline Tamanho do & Número & \multicolumn{3}{c}{ Estádio nuclear } \\
\cline { 3 - 5 } folículo $(\mathrm{mm})$ & de ovócitos & Vesícula germinativa $(\%)$ & Prometáfase $(\%)$ & Metáfase I $(\%)$ \\
\hline $1-2$ & 98 & $88(89,8) \mathrm{a}$ & $10(10,2) \mathrm{a}$ & $0(0,0) \mathrm{a}$ \\
$3-5$ & 101 & $91(90,1) \mathrm{a}$ & $7(6,9) \mathrm{a}$ & $3(2,9) \mathrm{a}$ \\
$6-8$ & 35 & $30(85,7) \mathrm{a}$ & $4(11,4) \mathrm{a}$ & $1(2,8) \mathrm{a}$ \\
$\geq 9$ & 7 & $7(100,0) \mathrm{a}$ & $0(0,0) \mathrm{a}$ & $0(0,0) \mathrm{a}$ \\
\hline
\end{tabular}

${ }^{1}$ Valores seguidos de mesma letra não diferem estatisticamente $(\mathrm{P}>0,05)$ pelo teste $\chi^{2}$.

TABELA 3. Número e estádio nuclear dos ovócitos obtidos de diferentes tamanhos de folículos após maturação in vitro por 24 horas, em vacas Nelore ${ }^{1}$.

\begin{tabular}{cccccccc}
\hline Tamanho do & Número de & \multicolumn{6}{c}{ Estádio nuclear } \\
\cline { 3 - 7 } $\begin{array}{c}\text { folículo } \\
(\mathrm{mm})\end{array}$ & ovócitos & $\begin{array}{c}\text { Vesícula } \\
\text { germinativa }(\%)\end{array}$ & $\begin{array}{c}\text { Prometáfase I } \\
(\%)\end{array}$ & $\begin{array}{c}\text { Metáfase I } \\
(\%)\end{array}$ & $\begin{array}{c}\text { Anáfase I } \\
(\%)\end{array}$ & $\begin{array}{c}\text { Telófase I } \\
(\%)\end{array}$ & $\begin{array}{c}\text { Metáfase II } \\
(\%)\end{array}$ \\
\hline $1-2$ & 321 & $5(1,6) \mathrm{a}$ & $9(2,8) \mathrm{a}$ & $13(4,0) \mathrm{a}$ & $4(1,2) \mathrm{a}$ & $4(1,2) \mathrm{a}$ & $285(88,8) \mathrm{a}$ \\
$3-5$ & 493 & $3(0,6) \mathrm{a}$ & $8(1,6) \mathrm{a}$ & $32(6,5) \mathrm{a}$ & $11(2,2) \mathrm{a}$ & $6(1,2) \mathrm{a}$ & $433(87,8) \mathrm{a}$ \\
$6-8$ & 70 & $0(0) \mathrm{a}$ & $1(1,4) \mathrm{a}$ & $2(2,9) \mathrm{a}$ & $1(1,4) \mathrm{a}$ & $1(1,4) \mathrm{a}$ & $65(92,9) \mathrm{a}$ \\
$\geq 9$ & 27 & $0(0) \mathrm{a}$ & $0(0) \mathrm{a}$ & $0(0) \mathrm{a}$ & $0(0) \mathrm{a}$ & $0(0) \mathrm{a}$ & $27(100,0) \mathrm{a}$ \\
\hline
\end{tabular}

${ }^{1}$ Valores seguidos de mesma letra não diferem estatisticamente $(\mathrm{P}>0,05)$ pelo teste $\chi^{2}$. 
e para o desenvolvimento futuro (Wassarman \& Albertini, 1994). Para que isso ocorra normalmente, o ovócito precisa ter adquirido a competência meiótica que ocorre na fase final do crescimento ovocitário. Ovócitos competentes necessitam ter estocado fatores importantes, na forma de proteína ou de mRNA estável, que serão utilizados durante a maturação, fecundação e desenvolvimento embrionário (Sirard \& Blodin, 1996). Quando os ovócitos são aspirados do folículo, a sua capacidade de sintetizar proteínas não é afetada, mas perdem a capacidade de fazer RNA em torno de duas horas após a aspiração, a não ser que o bloqueio da meiose possa ser mantida artificialmente (Sirard \& Coenen, 1994). Portanto, a competência deve ser adquirida antes da condensação nuclear, ou seja, antes da aspiração folicular.

Vários estudos com B. taurus têm mostrado a relação entre tamanho do folículo e a competência dos ovócitos (Pavlok et al., 1992; Lonergan et al., 1994; Sirard \& Blodin, 1996). Os resultados desses estudos sugerem que os folículos em crescimento devem atingir um tamanho mínimo de 3-4 mm para que os ovócitos sejam capazes de responder aos estímulos e realizar a maturação completa. A falta de competência observada em ovócitos de folículos menores foi atribuída à ausência de fatores encontrados no citoplasma e que se encontram presentes em ovócitos provenientes de folículos mais maturos. Essa suposição é sustentada pela constatação de que em ovócitos obtidos de folículos até $4 \mathrm{~mm}$ ainda há síntese de RNA (Fair et al., 1995) e que os ovócitos continuam crescendo por muito tempo após a formação do antro (Arlotto et al., 1996).

Entretanto, dados do presente estudo indicam haver diferenças com relação à aquisição da competência em zebuínos, visto que as taxas de maturação, penetração e clivagem foram semelhantes no tocante a ovócitos de folículos de $1 \mathrm{~mm}$ até $\geq 9 \mathrm{~mm}$. Além disso, não foi observado crescimento dos ovócitos em folículos $\geq 3 \mathrm{~mm}$. Embora os ovócitos de 1-2 mm tenham menor diâmetro do que os dos demais grupos, a capacidade de desenvolvimento foi semelhante. Esses dados sugerem a hipótese de que a competência para maturar em zebuínos é adquirida mais cedo ou com um tamanho menor de folículo em comparação com taurinos.

$\mathrm{Na}$ espécie $B$. taurus, sabe-se que mudanças dramáticas ocorrem no núcleo durante o período final da maturação, à medida que o folículo cresce de $1 \mathrm{~mm}$ a $15-20 \mathrm{~mm}$, e essas mudanças tem efeito crucial no potencial de desenvolvimento dos ovócitos (Lonergan et al., 1994). Portanto, é possível - pelo fato de o menor tamanho do folículo pré-ovulatório (12 mm) em zebuínos (Figueiredo et al., 1997) e o diâmetro do ovócito se estabilizarem em folículos de $3 \mathrm{~mm}$ - que essas mudanças se completem em folículos de menor tamanho.

Estudos mais aprofundados são necessários, para que possam estabelecer-se de forma mais conclusiva essas relações.

TABELA 4. Número e porcentagem de ovócitos, obtidos de diferentes tamanhos de folículos, que apresentavam penetração, por um espermatozóide, polispermia ( $\geq 2$ espermatozóides), descondensação da cabeça do espermatozóide, pronúcleos (um masculino e um feminino) e clivagem (duas células) após a maturação e fecundação in vitro, em vacas Nelore¹.

\begin{tabular}{ccccccc}
\hline $\begin{array}{c}\text { Tamanho do } \\
\text { folículo }(\mathrm{mm})\end{array}$ & $\begin{array}{c}\text { Número de } \\
\text { ovócitos }\end{array}$ & $\begin{array}{c}\text { Penetração } \\
(\%)\end{array}$ & $\begin{array}{c}\text { Polispermia } \\
(\%)\end{array}$ & $\begin{array}{c}\text { Descondensação } \\
\text { da cabeça }(\%)\end{array}$ & $\begin{array}{c}\text { Pronúcleos } \\
(\%)\end{array}$ & $\begin{array}{c}\text { Clivagem } \\
(\%)\end{array}$ \\
\hline $1-2$ & 196 & $183(93,4) \mathrm{a}$ & $10(5,5) \mathrm{a}$ & $1(0,5) \mathrm{a}$ & $21(11,5) \mathrm{a}$ & $150(81,9) \mathrm{a}$ \\
$3-5$ & 238 & $216(90,7) \mathrm{a}$ & $7(2,9) \mathrm{a}$ & $2(0,8) \mathrm{a}$ & $31(14,4) \mathrm{a}$ & $172(79,6) \mathrm{a}$ \\
$6-8$ & 69 & $63(91,3) \mathrm{a}$ & $4(6,3) \mathrm{a}$ & $3(4,8) \mathrm{a}$ & $9(14,3) \mathrm{a}$ & $49(77,8) \mathrm{a}$ \\
$\geq 9$ & 25 & $23(92,0) \mathrm{a}$ & $3(13,0) \mathrm{a}$ & $0(0) \mathrm{a}$ & $2(8,0) \mathrm{a}$ & $18(78,3) \mathrm{a}$ \\
\hline
\end{tabular}

${ }^{1}$ Valores seguidos de mesma letra não diferem estatisticamente $(\mathrm{P}>0,05)$ pelo teste $\chi^{2}$. 


\section{CONCLUSÃo}

Ovócitos de zebuínos obtidos de folículos de $1 \mathrm{~mm}$ até $\geq 9 \mathrm{~mm}$ podem ser utilizados para maturação e fecundação in vitro na espécie $B$. indicus.

\section{REFERÊNCIAS}

ARLOTTO, T.; SCHWATZ, J.-L.; FIRST, N.L.; LEIBFRIED-RUTLEDGE, M.L. Aspects of follicle and oocyte stage that affect in vitro maturation and development of bovine oocytes. Theriogenology, Los Altos, v.45, n.5, p.943-956, Apr. 1996.

BAR-AMIR, S.; TSAFRIRI, A. Acquisition of meiotic competence in the rat: role of gonadotropins and estrogen. Gamete Research, New York, v.4, p.463472,1981

CROZET, N.; AHMED-ALI, M.; DUBOS, M.P. Developmental competence of goat oocytes from follicles of different size categories following maturation, fertilization and culture in vitro. Journal of Reproduction and Fertility, Oxford, v.103, n.2, p.293-298, Mar. 1995.

DOMINGUEZ, M.M. Effect of body condition , reproductive status and breed on follicular population and oocyte quality in cows. Theriogenology, Los Altos, v.43, n.8, p.1405-1418, Jul. 1995.

EPPIG, J.J. Mammalian oocyte development in vivo and in vitro. In: WASSARMAN, P.W. (Ed.). Elements of mammalian fertilization. Boca Raton : CRC, 1991. p.57-76.

FAIR, T.; HYTTEL, P.; GREVE, T. Bovine oocyte diameter in relation to maturational competence and transcriptional activity. Molecular Reproduction and Development, New York, v.42, p.437-442, 1995.

FIGUEIREDO, R.A.; BARROS, C.M.; ROCHA, G.P.; PAPA, F. O. Prevalência de duas ondas de crescimento folicular ovariano em vacas da raça Nelore. Revista Brasileira de Reprodução Animal, Belo Horizonte, v.19, n.3/4, p.200-209, 1995.

FIGUEIREDO, R.A.; BARROS, C.M.; PINHEIRO, L.; SOLER, J.M.P. Ovarian follicular dynamics in Nelore breed (Bos indicus) cattle. Theriogenology, Los Altos, v.47, n.8, p.1489-1505, June 1997.
GANDOLFI, F.; LUCIANO, A.M.; MODINA, S.; PONZINI, A.; POCAR, P.; ARMSTRONG, D.T.; LAURIA, A. The in vitro developmental competence of bovine oocytes can be related to the morphology of the ovary. Theriogenology, Los Altos, v.48, n.7, p.1153-1160, Nov. 1997.

KIM, K.S.; MITSUMIZO, N.; FUJITA, K.; UTSUMI, $\mathrm{K}$. The effects of follicular fluid on in vitro maturation, oocyte fertilization on the development of bovine embryos. Theriogenology, Los Altos, v.45, n.4, p.787-799, Mar. 1996.

LONERGAN，P.; MONAGHAN，P.; RIZOS，D.; BOLAND, M.P.; GORDON, I. Effect of follicle size on bovine oocyte quality and developmental competence following maturation, fertilization, and culture in vitro. Molecular and Reproduction Development, New York, v.37, p.48-53, 1994.

MOTLIK, J.; CROZET, N.; FULKA, J. Meiotic competence in vitro of pig oocytes isolated from early antral follicles . Journal of Reproduction and Fertility, Oxford, v.72, n.2, p.323-328, Nov. 1984.

MUTIGA, E.R.; MUKASA-MUGERWA, E.; AZAG, T. Luteolytic effect of $\mathrm{PGF}_{2}$ alpha in Boran and Boran x Friesian cross-breed heifers. Journal of Agricultural Science, Lambridge, v.120, p.103-106, 1993.

PARRISH, J.J.; KROGENAES, A.; SUSKO-PARRISH, J.L. Effect of bovine sperm separation by swimup or percoll on success of in vitro fertilization and embryo development. Theriogenology, Los Altos, v.44, n.6, p.859-869, Oct. 1995.

PARRISH, J.J.; SUSKO-PARRISH, J.L.; LEIBFRIEDRUTLEDGE, M.L.; CRISTER, E.S.; EYESTONE, W.J.; FIRST, N.L. Bovine in vitro fertilization with frozen thawed semen. Theriogenology, Los Altos, v.25, n.4, p.591-600, Apr. 1986.

PAVLOK, A.; LUCAS-HAHN, A.; NIEMANN, H. Fertilization and developmental competence of bovine oocytes derived from different categories of antral follicles. Molecular Reproduction and Development, New York, v.31, p.63-67, 1992.

SAS INSTITUTE (Cary, EUA). SAS user's guide: basics. 5.ed. Cary, 1985. 1290p.

SIRARD, M.A.; BLODIN, P. Oocyte maturation and IVF in cattle. Animal Reproduction Science, Amsterdsam, v.42, n.1/4, p.417-426, Apr. 1996.

Pesq. agropec. bras., Brasília, v.35, n.1, p.207-214, jan. 2000 
SIRARD, M.A.; COENEN, K. Effects of inhibition of meiotic resumption upon the subsequent development of bovine oocytes in vitro. Journal of Reproduction and Development, Japan, v.41, p.255-262, 1994.

SMITH, L.C.; OLIVEIRA-ANGEL, M.; GROOME,N.P.; BHATIA, B.; PRICE, C. Oocyte quality in small antral follicles in the presence or absence of a large dominant follicle in cattle. Journal of Reproduction and Fertility, Oxford, v.106, n.2, p.193-199, Mar. 1996.

WASSARMAN, P.M.; ALBERTINI, D.F. The mammalian ovum. In: KNOBIL, E.; NEIL, J.D. (Eds.). The physiology of reproduction. New York : Raven, 1994. p.79-122. 